\title{
Bovine milk exosomes contain microRNA and mRNA and are taken up by human macrophages
}

\author{
Hirohisa Izumi, ${ }^{* 1}$ Muneya Tsuda, ${ }^{*}$ Yohei Sato, ${ }^{*}$ Nobuyoshi Kosaka, $†$ Takahiro Ochiya, $\dagger$ Hiroshi Iwamoto, \\ Kazuyoshi Namba, ${ }^{*}$ and Yasuhiro Takeda* \\ *Nutritional Science Institute, Morinaga Milk Industry Co. Ltd., Zama, Kanagawa 252-8583, Japan \\ †Division of Molecular and Cellular Medicine, National Cancer Center Research Institute, Chuo-ku, Tokyo, 104-0045, Japan
}

\begin{abstract}
We reported previously that microRNA (miRNA) are present in whey fractions of human breast milk, bovine milk, and rat milk. Moreover, we also confirmed that so many mRNA species are present in rat milk whey. These RNA were resistant to acidic conditions and to RNase, but were degraded by detergent. Thus, these RNA are likely packaged in membrane vesicles such as exosomes. However, functional extracellular circulating RNA in bodily fluids, such as blood miRNA, are present in various forms. In the current study, we used bovine raw milk and total RNA purified from exosomes (prepared by ultracentrifugation) and ultracentrifuged supernatants, and analyzed them using miRNA and mRNA microarrays to clarify which miRNA and mRNA species are present in exosomes, and which species exist in other forms. Microarray analyses revealed that most mRNA in milk whey were present in exosomes, whereas miRNA in milk whey were present in supernatant as well as exosomes. The RNA in exosomes might exert functional effects because of their stability. Therefore, we also investigated whether bovine milk-derived exosomes could affect human cells using THP-1 cells. Flow cytometry and fluorescent microscopy studies revealed that bovine milk exosomes were incorporated into differentiated THP-1 cells. These results suggest that bovine milk exosomes might have effects in human cells by containing RNA.
\end{abstract}

Key words: microRNA, mRNA, exosome, milk

\section{INTRODUCTION}

Bovine milk and dairy products have a long tradition and are a good source of nutrition to maintain human health (Haug et al., 2007). In additional to nutritional agents, milk also contains a large number of biological components, including cytokines, chemokines, and

Received November 5, 2014.

Accepted January 7, 2015.

${ }^{1}$ Corresponding author: h-izumi@morinagamilk.co.jp hormones (Cross and Gill, 2000; van Hooijdonk et al., 2000). In recent years, studies have revealed that human (Kosaka et al., 2010b; Weber et al., 2010; Zhou et al., 2012; Munch et al., 2013), bovine (Chen et al., 2010; Hata et al., 2010; Izumi et al., 2012, 2013; Sun et al., 2013), pig (Gu et al., 2012), and rat milk (Izumi et al., 2014) also contain microRNA (miRNA). Some of these studies reported that mRNA are also contained in whey (Hata et al., 2010; Izumi et al., 2012, 2013, 2014). Moreover, these RNA are stable under harsh conditions, such as low $\mathrm{pH}$, and in the presence of RNase (Hata et al., 2010; Kosaka et al., 2010b; Izumi et al., 2012). These RNA have been detected in commercial dairy products, such as powdered infant formula, that have undergone stringent industrial processes (Chen et al., 2010; Izumi et al., 2012). Based on these studies, it is possible that RNA in milk have functions in the mammalian gastrointestinal tract.

Most body fluids, such as blood, saliva, urine, and amniotic fluid, contain miRNA (Mitchell et al., 2008; Kosaka et al., 2010a; Weber et al., 2010; Argyropoulos et al., 2013; Ogawa et al., 2013). However, these circulating RNA exist in diverse forms, including packaged in exosomes (Simpson et al., 2009; Kosaka et al., 2010a; Lässer et al., 2011), in high-density lipoprotein (Vickers et al., 2011), and as complexes with RNA-binding proteins (Arroyo et al., 2011). For example, our previous study (Izumi et al., 2013) showed that the RNA concentration in bovine milk whey-derived exosomes was lower than was that in whey. Therefore, the aim of the current study was to clarify which miRNA and mRNA species in bovine milk whey are present in exosomes, and assess which species exist in other forms, using microarrays. No comprehensive reports have analyzed the presence of mRNA in bovine milk whey, although mRNA were found in rat milk whey (Izumi et al., 2014), human (Maningat et al., 2009; Lemay et al., 2013) and goat (Brenaut et al., 2012) milk fat globules, and bovine milk somatic cells (Wickramasinghe et al., 2012) using microarrays or next-generation sequencing. Our previous study using rat milk whey (Izumi et al., 2014) detected $>10,000 \mathrm{mRNA}$. Therefore, to our knowledge, 
the current study is the first report to reveal which mRNA are present in bovine milk whey exosomes and in other forms. Previous studies revealed that bovine milk miRNA profiles differ among cows and between colostrum and mature milk (Chen et al., 2010; Izumi et al., 2012). In commercial dairy products, raw milk is collected and mixed from many cows and is usually used. Whey is an important fraction of milk, and is also used in a variety of products (Marshall, 2004). In the current study, we prepared whey fractions from raw milk, which is used for commercial dairy products. In addition, some studies showed that macrophages could take up milk whey-derived exosomes (Lässer et al., 2011; Sun et al., 2013). Therefore, we also investigated whether bovine milk-derived exosomes could be taken up by human cells using human monocytic leukemia THP-1 cells that show macrophage-like functions after differentiation by phorbolmyristate acetate (PMA).

\section{MATERIALS AND METHODS}

\section{Milk Whey Sample Preparation}

Three bovine raw milk samples were prepared and stored at $-80^{\circ} \mathrm{C}$ until use; these are commonly used for research and development in our laboratory. Whey was prepared as described previously (Izumi et al., 2012, 2013). Briefly, the samples were centrifuged twice $(1,200$ $\times g, 4^{\circ} \mathrm{C}, 10 \mathrm{~min}$ ) to remove fat, cells, and large debris. The defatted supernatant was then centrifuged $(21,500$ $\times g, 4^{\circ} \mathrm{C}, 30 \mathrm{~min}, 1 \mathrm{~h}$ ) to remove residual fat and casein. The clear supernatant (whey) was then passed through $0.65-, 0.45-$, and $0.22-\mu \mathrm{m}$ filters to remove residual cell debris.

\section{Exosome and Supernatant Preparation}

The whey samples (see previous section) were ultracentrifuged $\left(100,000 \times g, 4^{\circ} \mathrm{C}, 90 \mathrm{~min}\right)$ using an SRP70AT rotor (Hitachi Koki, Tokyo, Japan) according to a previous study (Lässer et al., 2011). The resulting supernatant was collected carefully to avoid contaminating the pelleted exosomes. The pelleted exosomes were resuspended in PBS and then ultracentrifuged $\left(100,000 \times g, 4^{\circ} \mathrm{C}, 90 \mathrm{~min}\right)$ for washing; this wash step was performed twice. Finally, the exosomes were resuspended in PBS. The protein content of the exosomes was determined using a Micro Bradford protein assay (Bio-Rad, Hercules, CA).

\section{Extraction of Total RNA}

Total RNA was extracted from exosomes and supernatant samples, and was purified using an miRNeasy
Serum/Plasma Kit (Qiagen, Hilden, Germany) as described previously (Izumi et al., 2012, 2013, 2014). The quantity and integrity of the RNA were assessed using an RNA 6000 Pico Kit (Agilent Technologies, Santa Clara, CA), and the miRNA-to-small RNA ratio (default settings: miRNA $=10-40$ nucleotides; small RNA $=0-270$ nucleotides) was examined on an Agilent 2100 Bioanalyzer (Agilent) using a Small RNA Kit (Agilent).

\section{miRNA Microarray}

The RNA samples were derived from an equal mixture of 3 samples. To detect the expression of miRNA in exosomes and supernatant, $40 \mathrm{ng}$ of mixed total RNA was labeled with cyanine-3 and then hybridized to Bovine miRNA Microarray Rel. 17.0 arrays using an miRNA Complete Labeling Reagent and Hyb Kit (Agilent; Wang et al., 2007). The Bovine miRNA Microarray Rel. 17.0 analyzes the expression of 670 bovine miRNA from the Sanger miRBase Rel.17.0 (www.mirbase.org). Signals were detected with an Agilent DNA Microarray Scanner, and the scanned images were analyzed using the Feature Extraction Software (ver. 10.7.3.1; Agilent).

\section{mRNA Microarray}

The RNA samples were derived from an equal mixture of 3 samples. To detect the expression of mRNA in exosomes and supernatant, complementary RNA was generated from $100 \mathrm{ng}$ of mixed total RNA and then labeled with cyanine-3 using a Low Input Quick Amp Labeling Kit (Agilent). Labeled cRNA was hybridized to Bovine Oligo DNA Microarray ver. $2.0(4 \times 44 \mathrm{~K})$ using a Gene Expression Hybridization Kit (Agilent). The Bovine Oligo DNA Microarray ver. $2.0(4 \times 44 \mathrm{~K})$ contains 43,713 probes (without control probes). Signals were detected with an Agilent DNA Microarray Scanner, and the scanned images were analyzed using the Feature Extraction Software (ver. 10.7.3.1).

\section{Microarray Data Analysis}

Raw data from Feature Extraction Software were exported to GeneSpring GX ver. 11.5.1 (Agilent). Entities were considered present if signal was judged to be present by software. For mRNA microarray data, transcripts with raw signals $>20$ and that were given an Entrez Gene ID were considered to be present. All microarray data were deposited in the National Center for Biotechnology Information Gene Expression Omnibus (GEO), and are accessible through GEO Series accession number GSE61978 (www.ncbi.nlm.nih.gov/ geo). 


\section{Quantification of miRNA by $q P C R$}

The cDNA was generated using an miScript Reverse Transcription Kit (Qiagen). Briefly, total RNA from exosomes or supernatant (both from $3.2 \mathrm{~mL}$ of whey) was polyadenylated using poly $(\mathrm{A})$ polymerase, and cDNA was generated using reverse transcriptase and tagged oligo-dT primers. The cDNA was then diluted in 9 volumes of nuclease-free water and subjected to quantitative (q)PCR on a 7500 Fast Real-Time PCR System (Applied Biosystems, Foster City, CA) using an miScript SYBR Green PCR Kit and miScript Primer Assay (Qiagen) according to the manufacturer's instructions. This system was reported that show relatively high accuracy and high sensitivity among several quantification methods (Mestdagh et al., 2014) and was used in our previous studies (Izumi et al., 2012, 2013, 2014). The following real-time PCR protocol was used: initial activation of HotStarTaq DNA Polymerase (from miScript kit; $95^{\circ} \mathrm{C}, 15 \mathrm{~min}$ ); 40 to 50 cycles of denaturation $\left(94^{\circ} \mathrm{C}, 15 \mathrm{~s}\right)$, annealing $\left(55^{\circ} \mathrm{C}, 30 \mathrm{~s}\right)$, and extension $\left(70^{\circ} \mathrm{C}, 34 \mathrm{~s}\right)$; and melting curve analysis. The miScript Primer Assays (Qiagen) used for the target miRNA are listed in Supplemental Table S1 (http:// dx.doi.org/10.3168/jds.2014-9076). The data were analyzed using 7500 Software ver. 2.0.4. (Applied Biosystems) with the fixed cycle threshold $(\mathbf{C t})$ setting $(\Delta \mathrm{Rn}$ $=0.02$, where $\Delta \mathrm{Rn}$ is the fluorescence of the reporter dye minus the baseline) to assign baseline values and the threshold for $\mathrm{Ct}$ determination.

\section{Quantification of mRNA by $q P C R$}

The cDNA to quantify mRNA was generated from total RNA extracted from exosomes or supernatant (both from $3.2 \mathrm{~mL}$ of whey) using a High Capacity RNA-to-cDNA Kit (Applied Biosystems). The cDNA was diluted in 9 volumes of nuclease-free water, and was then subjected to qPCR on a 7500 Fast Real-Time PCR System (Applied Biosystems) using TaqMan Fast Advanced Master Mix (Applied Biosystems) and TaqMan Probes according to the manufacturer's protocol. The following real-time PCR protocol was used: uracil$\mathrm{N}$-glycosylase incubation $\left(50^{\circ} \mathrm{C}, 2 \mathrm{~min}\right)$, polymerase activation $\left(95^{\circ} \mathrm{C}, 20 \mathrm{~s}\right), 40$ to 50 cycles of denaturation $\left(95^{\circ} \mathrm{C}, 3 \mathrm{~s}\right)$, and annealing and extension $\left(60^{\circ} \mathrm{C}, 30\right.$ $\mathrm{s})$. The TaqMan Probes used for the target mRNA are listed in Supplemental Table S2 (http://dx.doi. org/10.3168/jds.2014-9076). The data were analyzed using 7500 Software ver. 2.0.4. (Applied Biosystems) with the fixed $\mathrm{Ct}$ setting $(\Delta \mathrm{Rn}=0.2)$ to assign baseline values and the threshold for $\mathrm{Ct}$ determination.

\section{Cell Culture}

The THP-1 cells were maintained in RPMI 1640 medium containing 10\% heat-inactivated FBS (HyClone, Logan, UT), $1 \%$ penicillin-streptomycin-glutamine (Gibco, Palo Alto, CA), 1\% NEAA (Gibco), and 0.1\% $\beta$-mercaptoethanol (Gibco; complete RPMI 1640). Cells were incubated at $37^{\circ} \mathrm{C}$ in humid atmosphere with $5 \%$ $\mathrm{CO}_{2}$. The FBS was ultracentrifuged $\left(100,000 \times g, 4^{\circ} \mathrm{C}\right.$, $90 \mathrm{~min}$ ) before use to eliminate bovine serum exosomes.

\section{Exosome Staining}

The exosomes were labeled with PKH67 Green Fluorescent Cell Linker Kit (Sigma-Aldrich, St. Louis, MO) according to the manufacturer's instructions and a previous study (Lässer et al., 2011), with minor modifications. Briefly, $8 \mu \mathrm{L}$ of PKH67 dye was added to $1 \mathrm{~mL}$ of Diluent $\mathrm{C}$ (from the kit), and was then added to the exosomes and the control sample (PBS). The samples were mixed gently for $4 \mathrm{~min}$, and then $2 \mathrm{~mL}$ of $2 \%$ FBS (exosome-depleted) Cell Wash (BD Biosciences, San Diego, CA) were added to bind the excess dye. The samples were then transferred to $100-\mathrm{kDa}$ filters (Amicon, Millipore, Billerica, MA). The samples were washed 3 times with $2 \%$ FBS (exosome-depleted) Cell Wash, before being transferred to new 100-kDa filters and washed twice with complete RPMI 1640 (see previous sections).

\section{Uptake of Milk-Derived Exosomes by THP-1 Cells}

The THP-1 cells were cultured in 12-well plate for flow cytometry and were cultured in 8-well Lab-Tek Chamber Slide (Thermo Fisher Scientific, Waltham, MA) for fluorescence microscopy. The THP-1 cells were differentiated using $50 \mathrm{n} M$ PMA (Sigma) for 60 $\mathrm{h}$ or were maintained without PMA, and were washed 3 times with complete RPMI. Ten micrograms of PKH67-labeled exosomes or the same volume of the PKH67-PBS control was added per $1 \times 10^{5}$ cells (differentiated or undifferentiated THP-1 cells), which were then incubated for $2 \mathrm{~h}$ at either $37^{\circ} \mathrm{C}$ or $4^{\circ} \mathrm{C}$. The incorporation of exosomes into the macrophages was analyzed using FACSCanto (BD Biosciences) and visualized using a fluorescence microscope BX53 (Olympus, Tokyo, Japan). For flow cytometry, cells were washed twice with PBS, treated with $0.05 \%$ trypsin- $0.02 \%$ EDTA-4Na solution (Gibco), washed twice with $2 \%$ FBS (exosome-depleted) Cell Wash, and suspended in $2 \%$ FBS (exosome-depleted) Cell Wash. The data were then acquired using FACSCanto. The flow cytometric data were analyzed using the FlowJo software (Tree 
Star Inc., Ashland, OR). For fluorescence microscopy, cells were washed twice with PBS, fixed with CellFIX (BD Biosciences) for $15 \mathrm{~min}$, and washed 3 times with PBS. Five microliters of 7-AAD (BD Biosciences) in $200 \mu \mathrm{L}$ of PBS was added for 15 min to label nuclei, and the samples were mounted using Vectashield (Vector Laboratories Inc., Burlingame, CA). The fluorescence microscopy data were analyzed using cellSens (Olympus).

\section{Statistical Analyses}

The values are expressed as mean \pm SEM. The significance of differences was determined using $t$-test for comparisons between 2 groups, and the Tukey-Kramer honestly significant difference (HSD) test was used for multiple comparisons (JMP software; SAS Institute Inc., Cary, NC). A $P$-value $<0.05$ was considered significant difference.

\section{RESULTS}

\section{Bioanalyzer Analyses}

Total RNA was extracted from bovine milk wheyderived exosomes and ultracentrifuged supernatant, and was analyzed using a bioanalyzer. No or very little ribosomal RNA (18S and $28 \mathrm{~S}$ ) was seen, but small RNA ( $<300$ nucleotides) were present (Figure 1). The RNA concentration in the exosome fraction was significantly higher than was that in the supernatant fraction (Figure 2A). The RNA content ratio of exosomes to supernatant was $\sim 7: 3$ (Figure $2 \mathrm{~B}$ ). The miRNA-tosmall RNA ratio (default setting: miRNA $=10-40$ nucleotides; small RNA $=0-270$ nucleotides) was significantly higher in the supernatant fraction compared with the exosome fraction (Figure $2 \mathrm{C}$ ).

\section{Microarray Analyses}

The miRNA microarray analyses revealed 79 miRNA in the exosomes, and 91 in the supernatant (Figure $3 \mathrm{~A})$. A total of 39 miRNA were common to both fractions (Figure 3A), but their signal intensities differed (Figure 3B). The top 50 highly expressed miRNA in exosomes and supernatant, and their normalized signal intensities, are listed in Table 1. The miRNA that were expressed at high levels differed between exosomes and supernatant (Table 1). The mRNA microarray analyses detected 19,320 mRNA probes in exosomes and 2,634 mRNA in supernatant (Figure 3C). A total of 2,538 mRNA probes (most of the mRNA probes that were detected in supernatant) were common to both exosomes and supernatant (Figure 3C); however, the signal intensity differed between fractions (Figure 3D). The top 50 highly expressed mRNA probes and their signal intensities in exosomes and supernatant are listed in Tables 2 and 3, respectively. Some mRNA probes were expressed highly in both exosomes and supernatant. However, most of highly expressed mRNA probes were different between exosomes and supernatant (Tables 2 and 3 ).

\section{qPCR Analyses of miRNA}

Twenty miRNA were selected from the top 50 list (Table 3) and were analyzed using qPCR to assess their expression levels in exosomes and supernatants that were isolated from the same volume of whey (Figure 4). Almost all of the selected miRNA (except for miR-133b and miR-1281) were expressed at significantly higher levels in exosomes compared with supernatants.

\section{qPCR Analyses of $m R N A$}

Twenty-three mRNA were selected from those shown in Tables 2 and 3, and were analyzed using qPCR to quantify their expression in exosomes and supernatants that were isolated from the same volume of whey (Figure 5). The selected mRNA were milk- and milk-derived exosome-related mRNA (Figure 5A, B) or mRNA that were reported in other studies to be milk RNA (milk cells and milk fat globule; Figure 5C; Maningat et al., 2009; Brenaut et al., 2012; Wickramasinghe et al., 2012; Lemay et al., 2013). All the selected mRNA were expressed at significantly higher levels in exosomes compared with supernatants (Figure 5).

\section{Cell-Based Experiments}

Fluorescence microscopy revealed that bovine raw milk-derived exosomes were taken up by differentiated THP-1 cells (Figure 6A-C). The extent of exosome incorporation into THP-1 cells was analyzed using flow cytometry. Undifferentiated THP-1 cells did not take up exosomes. In contrast, differentiated THP-1 cells (macrophage-like) could uptake exosomes at both 4 and $37^{\circ} \mathrm{C}$; however, exosome incorporation was significantly higher at 37 than at $4^{\circ} \mathrm{C}$ (Figure $\left.6 \mathrm{D}\right)$.

\section{DISCUSSION}

Extracellular circulating RNA can be present in forms other than exosomes and microvesicles (Simpson et al., 2009; Kosaka et al., 2010a; Arroyo et al., 2011; Lässer et al., 2011; Vickers et al., 2011). In the current study, data revealed that RNA were also present in ultracentrifuged supernatants of whey fraction (Figure 
RNA6000

Pico Kit

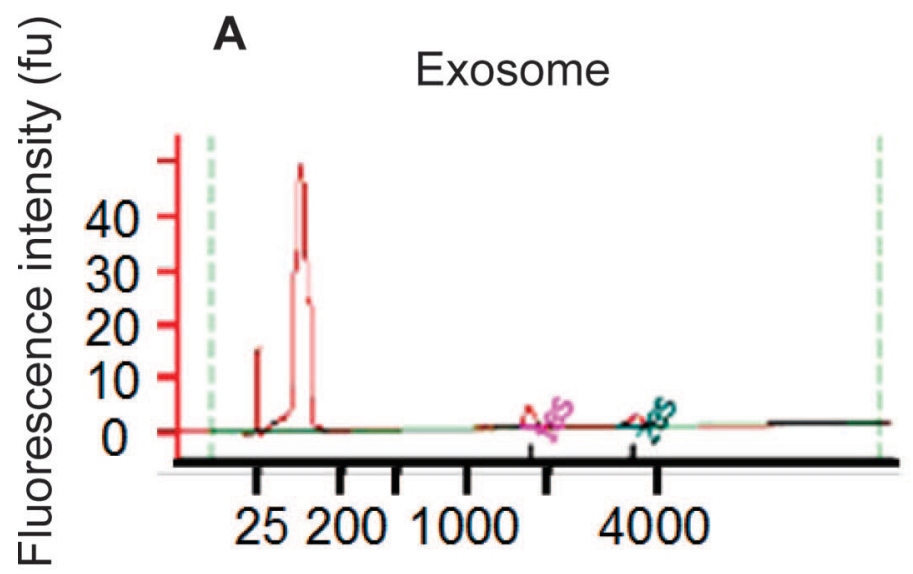

Small RNA

Kit
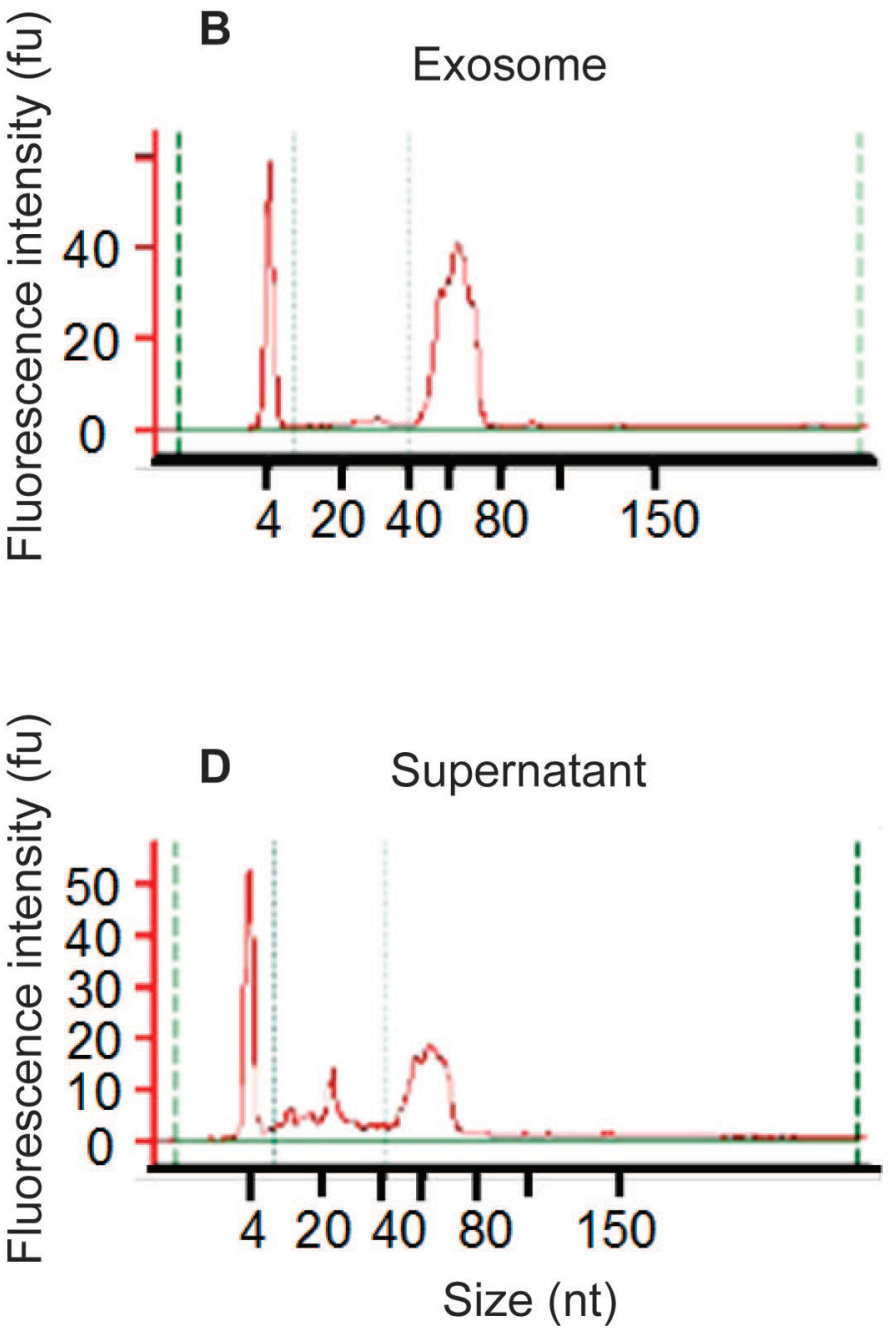

Figure 1. Analysis of RNA purified from bovine raw milk whey-derived exosomes and ultracentrifuged supernatants using Bioanalyzer (Agilent Technologies, Santa Clara, CA). (A, B) Bovine raw milk whey-derived exosomes; (C, D) ultracentrifuged supernatants from bovine raw milk whey. A and $\mathrm{C}$ were analyzed using an RNA 6000 Pico Kit (Agilent); B and D were analyzed using a Small RNA Kit (Agilent). fu = fluorescence unit; $\mathrm{nt}=$ nucleotide. Color version available online.

1), although the RNA concentration was significantly lower in supernatants compared with exosomes (Figure $2 \mathrm{~A})$. In addition, the RNA content ratio of exosome to supernatant was $\sim 7: 3$ (Figure $2 \mathrm{~B}$ ); therefore, most RNA was present in exosomes. Ninety-one miRNA were detected in the supernatant; however, 52 miRNA of these were present in only the supernatant. Therefore, the miRNA expression pattern differed between the supernatant and exosomes (Figure 3A, B).

Most (2,538 mRNA transcripts) mRNA detected in the supernatant were also present in exosomes, and the detected number of mRNA only in the supernatant was very few (96 mRNA transcripts), although 2,634 mRNA transcripts were detected in supernatant (Figure 3C). In contrast, large numbers of mRNA $(19,320 \mathrm{mRNA}$ transcripts) were present in exosomes. Therefore, it might be thought that most mRNA detected in milk whey were concentrated in exosomes.

The 50 miRNA expressed at the highest level in exosomes and supernatant according to microarrays are presented in Table 1. Fourteen miRNA (miR-2478, miR-2412, miR-2305, miR-2881, miR-2328*, miR-2888, miR-2304, miR-2391, miR-2892, miR-2887, miR-2316, miR-2374, miR-2291, miR-2284l) in exosomes and 28 miRNA (miR-2305, miR-2412, miR-2888, miR-2316, miR-2328*, miR-2478, miR-2893, miR-2881, miR-2374, 
A

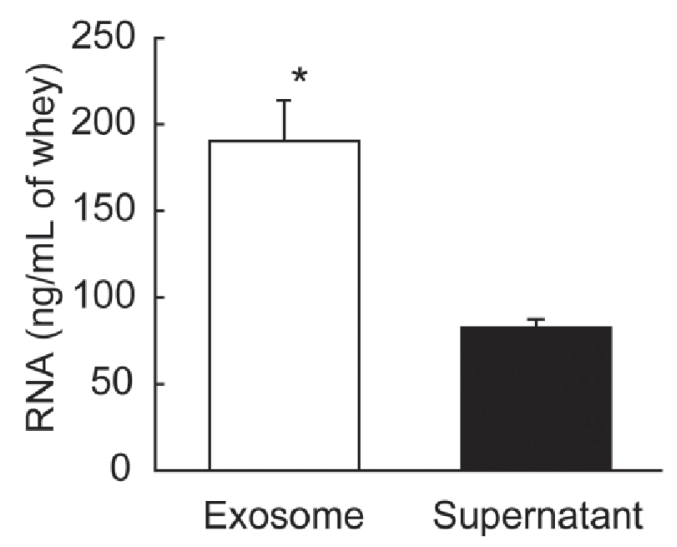

B

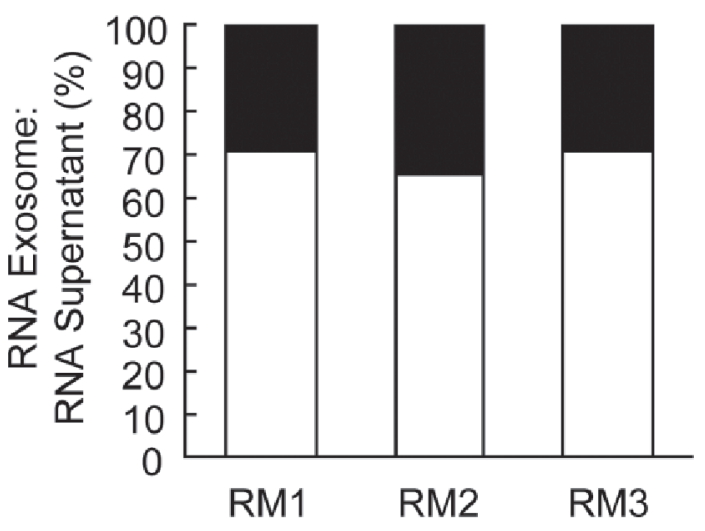

C

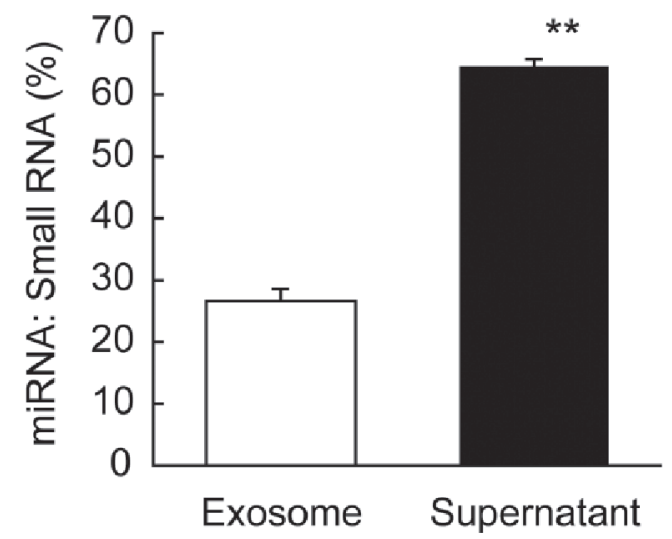

Figure 2. RNA concentrations, RNA concentrate ratio, and microRNA (miRNA)-to-small RNA ratio in bovine raw milk whey. (A) RNA concentrations in bovine raw milk whey-derived exosomes and ultracentrifuged supernatants; (B) ratios of the RNA concentrations in exosomes to those in supernatants from 3 raw milk (RM) whey samples; (C) miRNA-to-small RNA ratio. The values are means \pm SEM $(\mathrm{n}=3) .{ }^{*} P<0.05$ (compared with supernatant), ${ }^{*} * P<0.01$ (compared with exosome).
miR-2391, miR-2348, miR2892, miR-2885, miR-2428, miR-2882, miR-2486, miR-2455, miR-2898, miR-2407, miR-2436-5p, miR-2389, miR-2309, miR-2340, miR2902, miR-2454, miR-2373*, miR-2899, miR-2300a-5p) in supernatant are bovine-specific. Generally, speciesspecific miRNA are likely to be evolutionally younger and expressed at lower levels than highly conserved miRNA. The biological roles of these miRNA are unknown; however, some (miR-2478, miR-2412, miR-2305, miR-2881, miR-2328*, miR-2888, miR-2391, miR-2374, miR-2882, miR-2455, miR-2898) are predicted to regulate carbohydrate or lipid metabolism (Romao et al., 2014). Zhou et al. (2012) and Gu et al. (2012) reported the top 10 miRNA expressed in human and in pig milk exosomes, respectively. Seven (miR-148a, miR-30b-5p, let-7f, miR-29a, let-7a, miR-141, and miR-200a) of the top 10 miRNA in human milk exosomes and 5 miRNA (miR-148a, miR-30a-5p, miR-30d, miR-200c, and let7a) from pig milk exosomes were also present in the 50 miRNA expressed at the highest levels in bovine milk exosomes. Nevertheless, 14 of the top 50 miRNA were bovine-specific. These results suggest that milk exosome miRNA have some common roles among species, whereas other functions are species-specific. The biological functions of most miRNA remain unknown. In the current study, we selected 20 miRNA from the top 50 whose function was relatively well characterized (Table 1) and quantified them using qPCR in exosomes and supernatants that were isolated from the same volume of whey (Figure 4). Data revealed almost all of the miRNA (except for miR-133b and miR-1281) were expressed at significantly higher levels in exosomes than in supernatants. Both miR-133b and miR-1281 were among the 50 species expressed at the highest levels in supernatants, but not in exosomes. Therefore, these data do not contradict the microarray results because we used same amount of RNA from exosomes and supernatants in the microarrays. Two miRNA (miR-148a and let-7a) are common in human and pig milk exosomes (Gu et al., 2012; Zhou et al., 2012). These 2 miRNA were also expressed highly in bovine raw milk exosomes (Table 1, Figure 4). A previous study reported that miR-148a is a negative regulator of the innate immune response and antigen-presenting function of dendritic cells (Liu et al., 2010). It is also upregulated during intestinal cell differentiation (Hino et al., 2008), and targets DNA methyltransferase 3b (Sato et al., 2011). Let-7a inhibits Th17 differentiation by downregulating IL-6 secretion (Zhang et al. 2013). In addition, let-7a is upregulated during intestinal cell differentiation (Papetti and Auqenlicht, 2011). It is very interesting that the miRNA that are expressed highly in milk exosomes from several species exhibit common functions, such as regulating immune function and intestinal maturation. 
A

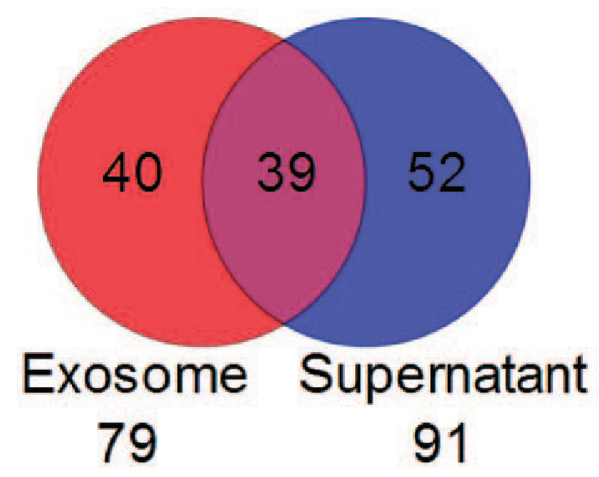

C

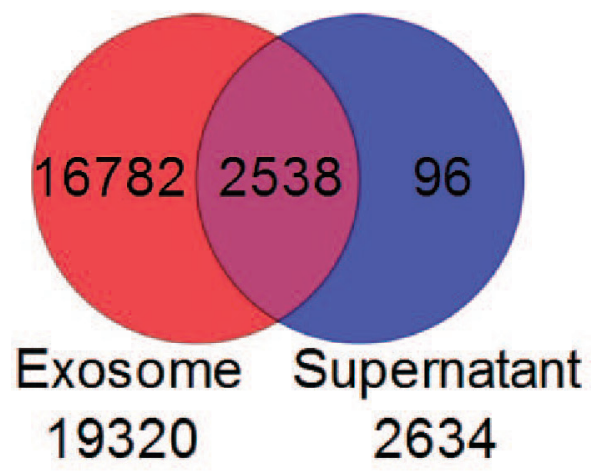

B
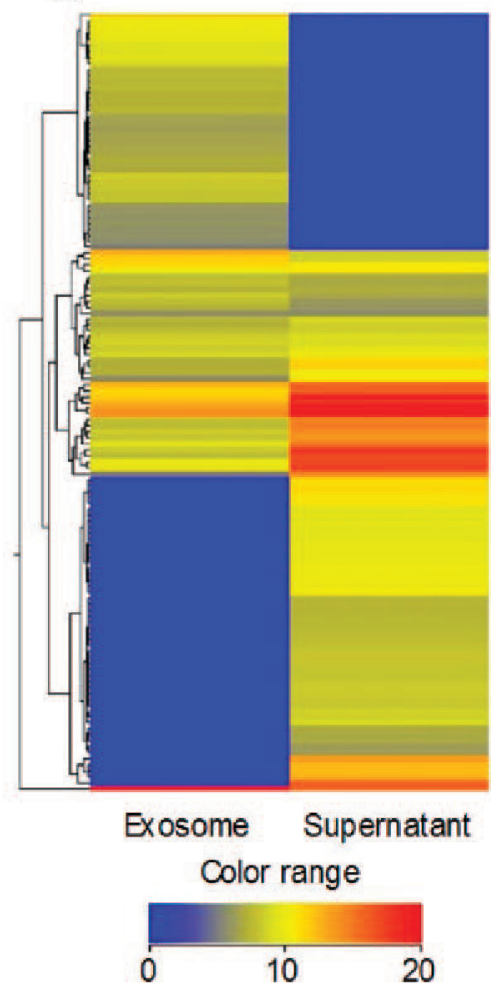

D

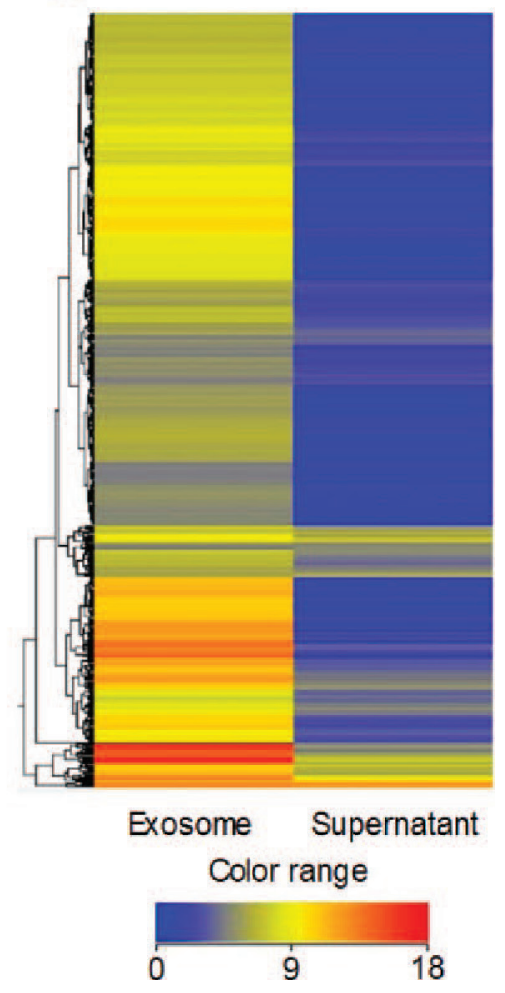

Figure 3. MicroRNA (miRNA) and mRNA microarray results of bovine raw milk whey-derived exosomes and ultracentrifuged supernatants. (A) Venn diagram showing the numbers of miRNA expressed in exosomes and supernatants; (B) heat map of the normalized array data for miRNA detected in exosomes or supernatants; (C) Venn diagram showing the numbers of mRNA probes expressed in exosomes and the supernatants; (D) heat map of the normalized array data for mRNA detected in exosomes or supernatants. 
Table 1. Top 50 most highly expressed microRNA in bovine whey exosome or supernatant

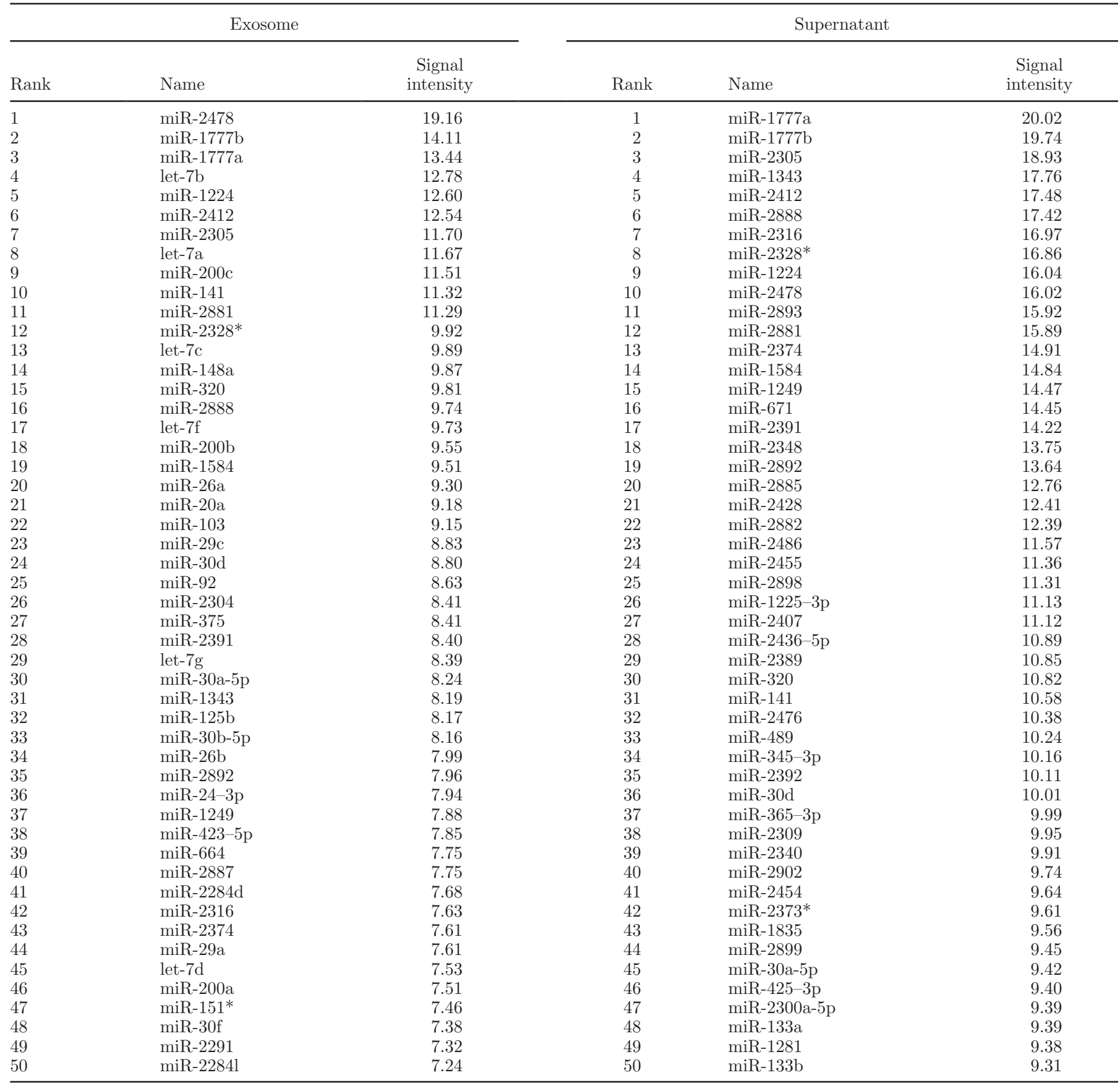

The 50 mRNA that were expressed at the highest level in exosomes and supernatants according to microarrays are shown in Tables 2 and 3, respectively. Most of mRNA expressed in exosomes are milk protein- and ribosomal protein-related mRNA. We observed similar results with rat milk whey-derived mRNA previously (Izumi et al., 2014). Consistent with this, previous microarray analysis of RNA extracted and purified from rat milk whey revealed that milk protein-derived and ribosomal mRNA transcripts were expressed highly (Izumi et al., 2014). Few studies of milk mRNA have been conducted. However, Maningat et al. (2009) and Lemay et al. (2013) studied human milk fat-derived mRNA. Both of these studies showed that milk proteinand ribosomal protein-related mRNA transcripts were expressed highly in the milk fat layer (Maningat et al., 2009; Lemay et al., 2013). However, Wickramasinghe et al. (2012) reported that no ribosomal protein-related 
Table 2. Top 50 most highly expressed mRNA probes in bovine whey exosome

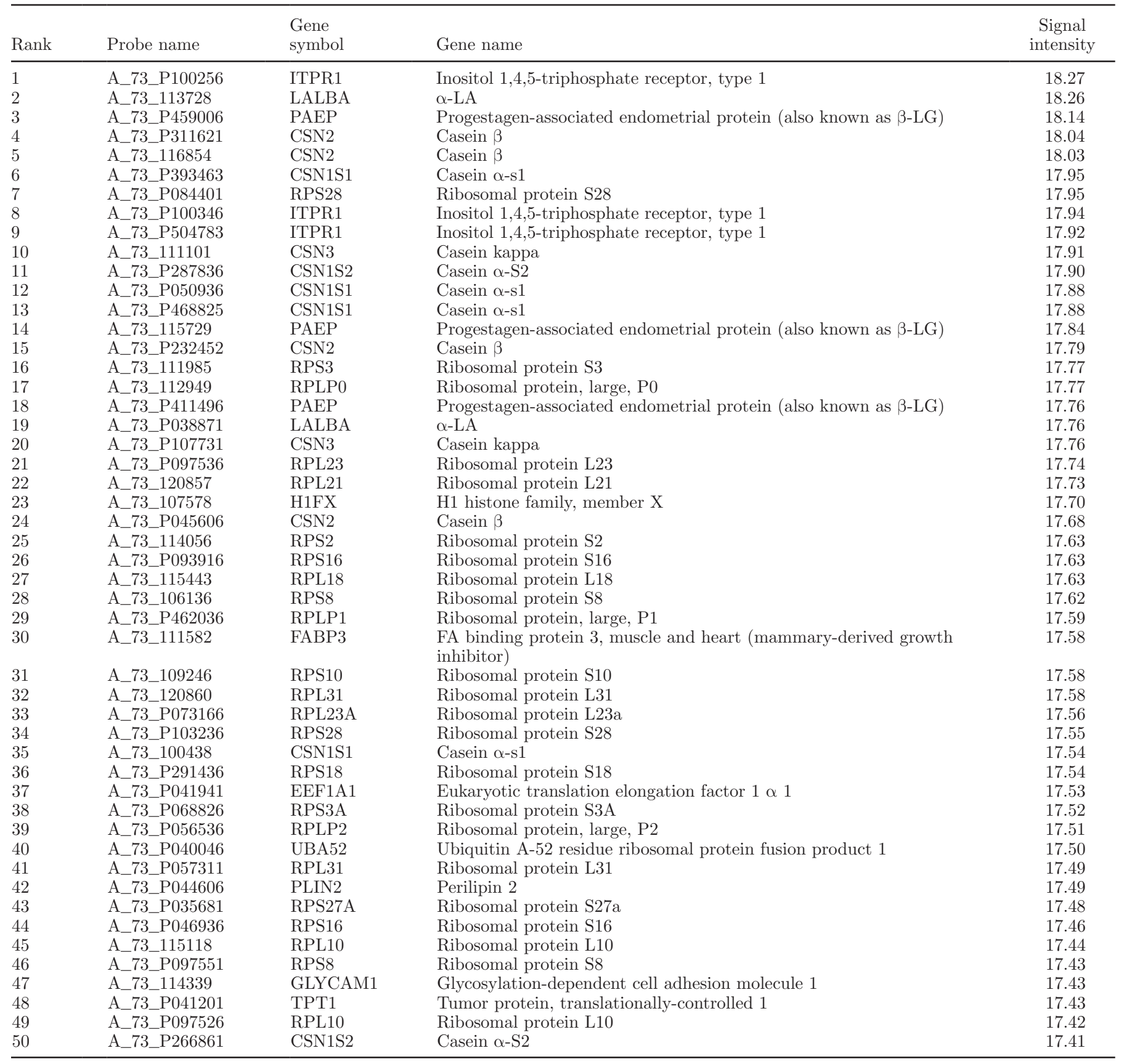

mRNA were among the 7 mRNA species expressed at the highest level in bovine milk somatic cells (cells from 15, 90, and $250 \mathrm{~d}$ of lactation), although milk proteinrelated mRNA were included in the list. These results suggest that some roles of mRNA might be common to milk whey, milk whey-derived exosomes, the milk fat layer, and milk cells, whereas others might differ or the roles of milk mRNA might differ among species.

In the current study, a large number of mRNA transcripts $(19,320 \mathrm{mRNA}$ transcripts) were detected in exosomes. However, selecting specific mRNA transcripts is challenging. Therefore, we selected milk protein-, milk-derived exosome-, and milk fat layer-related mRNA that were expressed at high levels in milk whey, the milk fat layer, or in milk somatic cells in previous studies (Maningat et al., 2009; Izumi et al., 2012, 2014; Wickramasinghe et al., 2012; Lemay et al., 2013). These mRNA transcripts were then analyzed in exosomes and supernatants isolated from same volume of whey using qPCR (Figure 5). Data revealed that all mRNA were 
Table 3. Top 50 most highly expressed mRNA probes in bovine whey supernatant

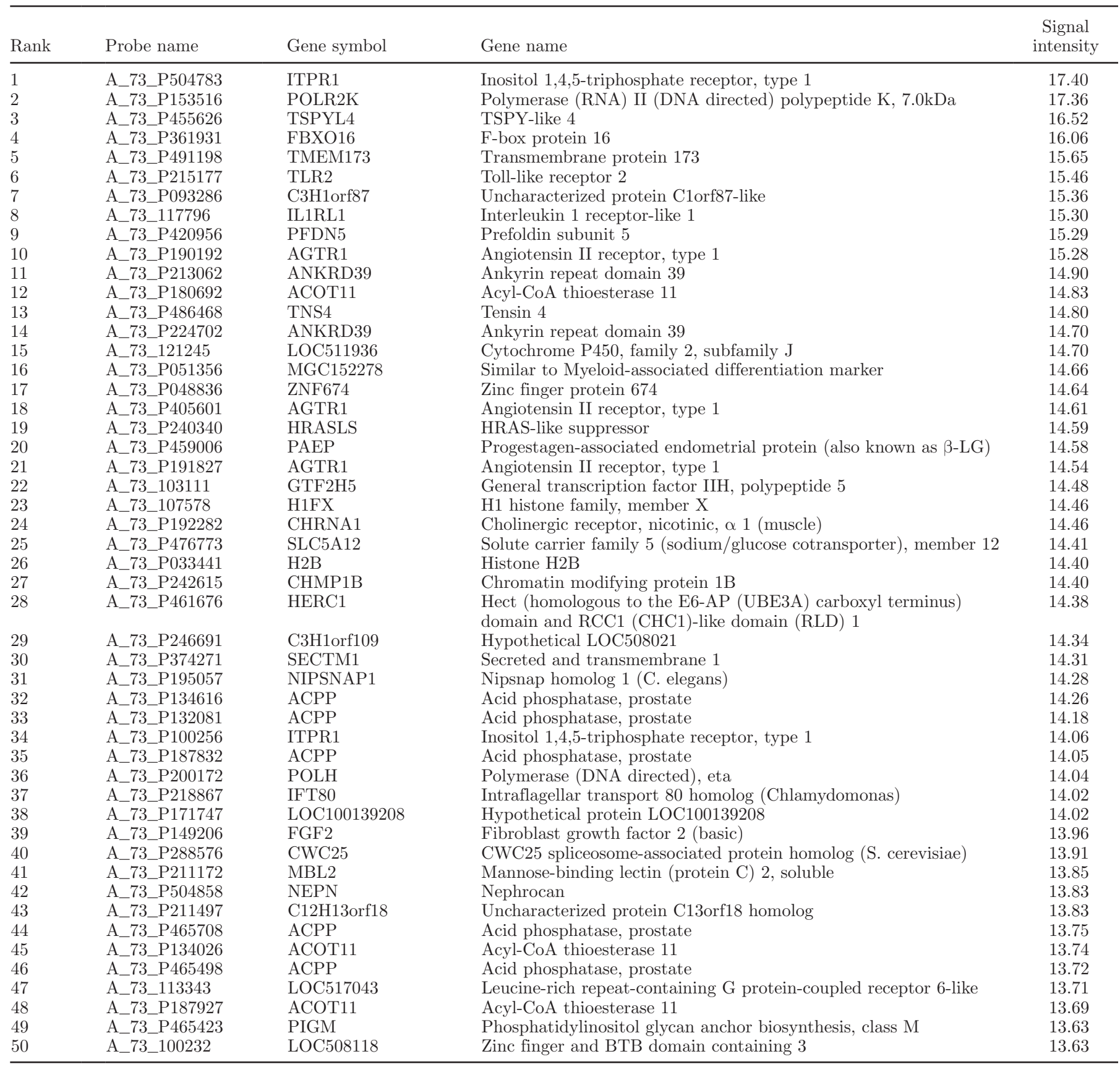

expressed at significantly higher levels in exosomes than in supernatants. Among the selected mRNA, some transcripts were expressed highly in bovine milk somatic cells and the human milk fat layer in previous reports (Maningat et al., 2009; Wickramasinghe et al., 2012; Lemay et al., 2013), but were not listed among the 50 highly expressed transcripts in exosomes in the current study. These results support the hypothesis that mRNA might be concentrated in exosomes. Unfortunately, in the current study, we did not investigate the presence of forms of RNA in supernatant in detail or the size range of exosomes. We prepared exosomes by ultracentrifugation (most commonly used method); however, the size of exosomes ranges widely. Thus, it is possible that extensively small or light exosomes remained in supernatant. It might be the reason that small numbers of mRNA detected in supernatant.

Exosomes isolated from bovine milk could be taken up by human macrophages (Figure 6). Consistent with this, Lässer et al. (2011) reported that exosomes from 


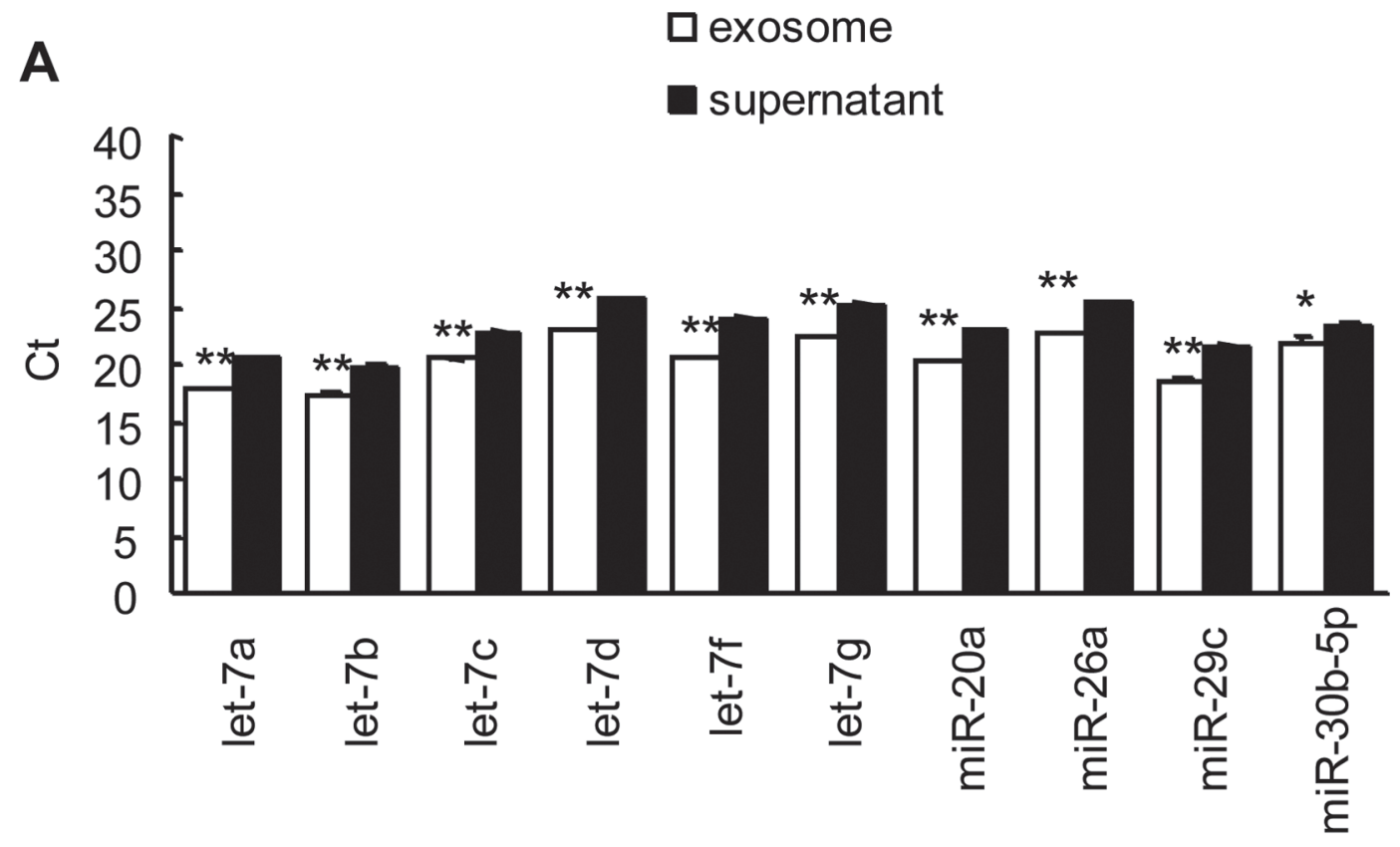

B

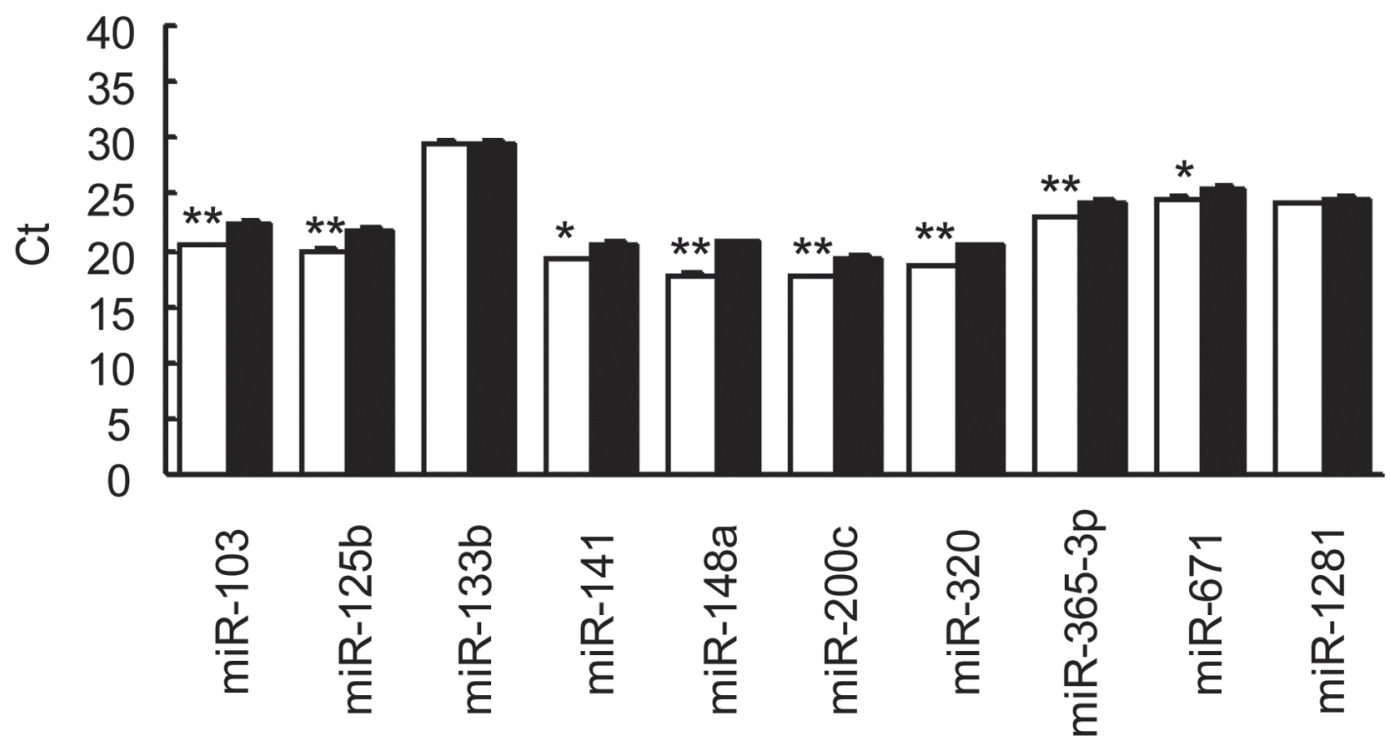

Figure 4. Quantitative PCR analysis [cycle threshold (Ct) values] of select microRNA (miRNA) in exosomes and supernatants isolated from equal volumes of bovine raw milk whey. Total RNA from exosomes and supernatants isolated from $3.2 \mathrm{~mL}$ of raw milk whey was used. The values are means \pm SEM $(\mathrm{n}=3) ;{ }^{*} P<0.05$ (compared with supernatant), ${ }^{* *} P<0.01$ (compared with supernatant).

human breast milk could be taken up by human macrophages. Moreover, Sun et al. (2013) reported that bovine milk exosomes could be taken up by murine macrophages, and that the functions of macrophages that incorporated bovine milk exosomes were altered. This suggests that human cells can uptake exosomes from other species, which is consistent with the current results.

It remains unknown whether milk-derived exosomes exert functions in vivo. However, previous studies, including those from our laboratory, showed that milk whey-derived RNA are resistant to acidic conditions 
A

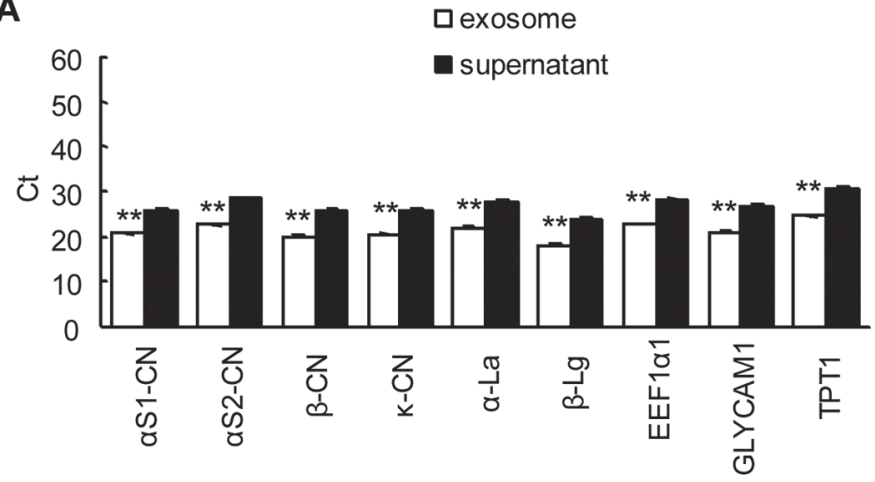

B

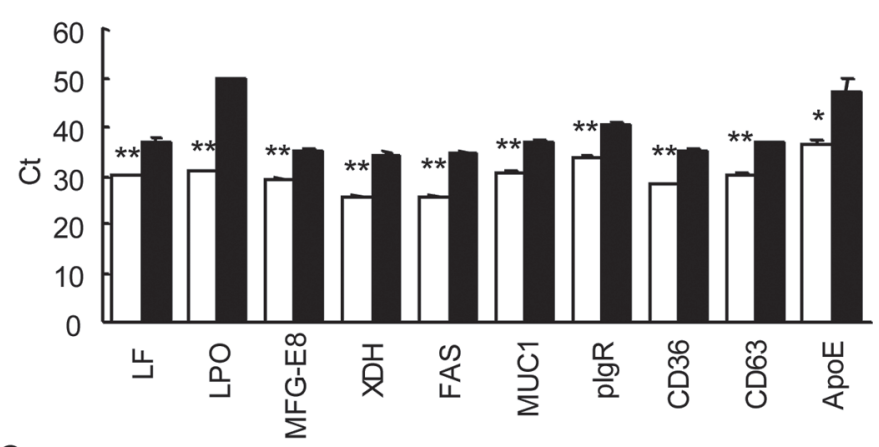

C

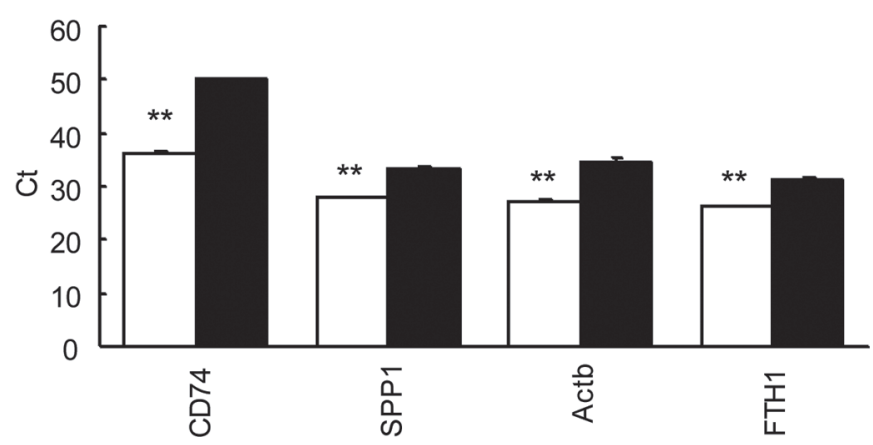

Figure 5. Quantitative PCR analysis [cycle threshold $(\mathrm{Ct})$ values of select mRNA in exosomes and supernatants isolated from equal volumes of bovine raw milk whey. Total RNA from exosomes and supernatants from $3.2 \mathrm{~mL}$ of raw milk whey was used. (A) Selected transcripts from the 50 species expressed at the highest level in exosomes; (B) milk-derived exosome-related transcripts; (C) selected transcripts identified in previous studies of milk somatic cells and the milk fat layer. The values are the mean $\pm \operatorname{SEM}(\mathrm{n}=3) ;{ }^{*} P<0.05$ (compared with supernatant), ${ }^{* *} P<0.01$ (compared with supernatant). Actb $=\beta$-actin; EEF $1 \alpha 1=$ eukaryotic translation elongation factor $1 \alpha$ $1 ; \mathrm{FAS}=$ fatty acid synthase FTH1 = ferritin, heavy polypeptide 1; GLYCAM1 = glycosylation-dependent cell adhesion molecule 1; LF = lactoferrin; $\mathrm{LPO}=$ lactoperoxidase; MFG-E8 = milk fat globule-EGF factor $8 ; \mathrm{MUC1}=$ mucin $1 ; \mathrm{pIgR}=$ poly $\mathrm{Ig}$ receptor; $\mathrm{SPP} 1=$ secreted phosphoprotein 1 ; TPT $1=$ tumor protein, translationally controlled 1 ; $\mathrm{XDH}=$ xanthine dehydrogenase; CD36 = cluster of differentiation 36, $\mathrm{CD} 63=$ cluster of differentiation 63; ApoE $=$ apolipoprotein $\mathrm{E}, \mathrm{CD} 74$ $=$ cluster of differentiation 74 .

and RNase (Hata et al., 2010; Kosaka et al., 2010b; Izumi et al., 2012). Therefore, it is possible that bovine milk-derived exosomes could exert functions in human body. In recent years, studies demonstrated that foodderived miRNA could be incorporated and exert function in vivo. For example, Zhang et al. (2012) reported that osa-MIR-168a (from rice) could be detected in human and mouse sera, and osa-MIR-168a decreased lowdensity lipoprotein receptor adapter protein $1 \mathrm{mRNA}$ (the predicted target mRNA of osa-MIR-168a) in the mouse liver. In addition, Ju et al. (2013) reported that grape exosome-like nanoparticles mediate intestinal tissue remodeling to induce intestinal stem cells and protect intestinal tissue from dextran sulfate sodiuminduced colitis. Moreover, Lukasik and Zielenkiewicz (2014) reported that some miRNAs from Arabidopsis thaliana, Picea abies, Populus trichocarpa, Brachypodium distachyon, and Zea mays were present in human and porcine breast milk exosomes by analyzing publically available data obtained from high-throughput sequencing using bioinformatics. In contrast, studies regarding the bioavailability of plant-borne miRNA in humans are controversial (Dickinson et al., 2013; Snow et al., 2013). Recently, Baier et al. (2014) reported that meaningful amounts of miRNA were detected in plasma isolated from healthy human subjects after the ingestion of nutritionally relevant doses of cow milk. They also revealed that Brassica-specific miRNA could not be detected in a broccoli sprout-feeding study. Therefore, it is important to consider why only milkborne miRNA were absorbed. In the current study, we showed that human macrophages could take up bovine raw milk-derived exosomes. However, it is unknown whether bovine raw milk-derived exosomes are taken up by only macrophages.

In conclusion, the current study demonstrated that most mRNA in bovine raw milk whey were present in exosomes, whereas miRNA were present both in exosomes and in other forms. Most miRNA and mRNA that are present in bovine raw milk whey were expressed at significantly higher levels in exosomes than in other forms. In addition, human macrophages could uptake bovine raw milk whey-derived exosomes. Moreover, a recent study (Baier et al., 2014) suggested that functional RNA in milk exert functions in the human body. However, it is unclear whether bovine raw milk whey-derived exosomes affect the function of macrophages. Moreover, the different size exosomes contain different types of RNA and other exosome-like vesicles (e.g., ectosomes) might be contained in milk-derived exosomes. As such, several aspects of milk-derived RNA remain unclear. Bovine raw milk is used widely in many dairy products and is an important food source. Therefore, additional studies regarding the physiological and biological roles of these functional RNA are needed. The current data describing RNA in bovine raw milk whey-derived exosomes might facilitate future studies. 
A

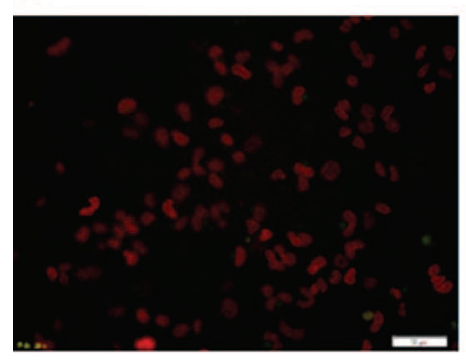

B

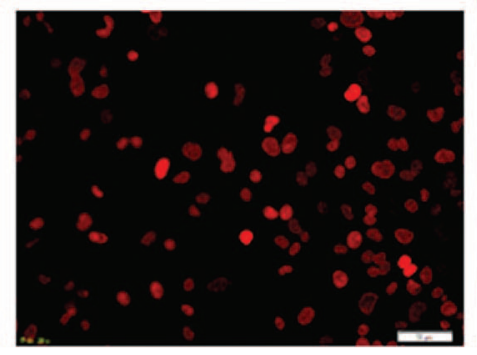

C

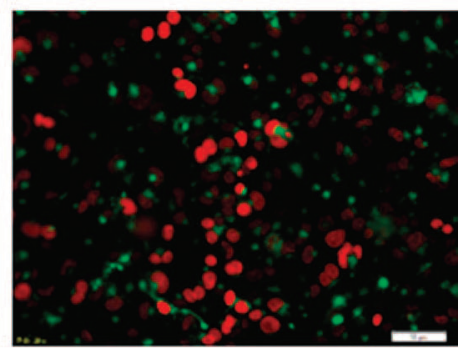

D

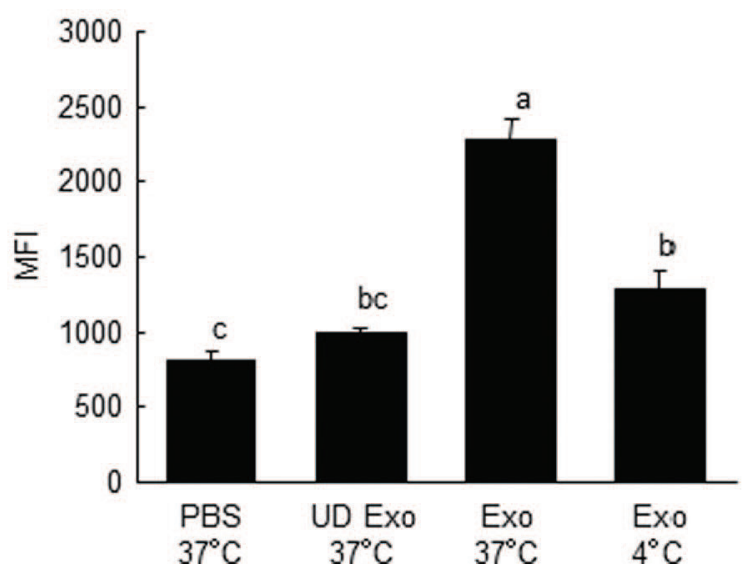

Figure 6. Uptake of bovine raw milk whey-derived exosomes by macrophages. (A-C) Fluorescence microscopy images; 7-AAD (BD Biosciences, San Diego, CA) was used to label the nuclei of THP-1 cells (red), and PKH67 (Sigma-Aldrich, St. Louis, MO) was used to label the exosomes (green). (A) PBS-PKH67 was added to differentiated THP-1 cells, followed by incubation at 37 C. (B) PKH67-labeled exosomes were added to differentiated THP-1 cells, followed by incubation at $4^{\circ} \mathrm{C}$. (C) PKH67-labeled exosomes were added to differentiated THP-1 cells, followed by incubation at $37^{\circ} \mathrm{C}$. (D) The uptake of fluorescence-labeled exosomes into THP-1 cells at various conditions was evaluated using a flow cytometer. PBS $37^{\circ} \mathrm{C}$ : PBS-PKH67 was added to differentiated THP-1 cells and cells were incubated at $37^{\circ} \mathrm{C}$. UD Exo $37^{\circ} \mathrm{C}$ : PKH67-labeled exosomes were added to undifferentiated THP-1 cells, followed by incubation at $37^{\circ} \mathrm{C}$. Exo $37^{\circ} \mathrm{C}$ : PKH67-labeled exosomes were added to differentiated THP-1 cells, followed by incubation at $37^{\circ} \mathrm{C}$. Exo $4^{\circ} \mathrm{C}$ : PKH67-labeled exosomes were added to differentiated THP-1 cells, followed by incubation at $4^{\circ} \mathrm{C}$. The values are the mean \pm SEM $(\mathrm{n}=3)$. Means without common letter $(\mathrm{a}-\mathrm{c})$ differ significantly $(P<0.05)$. Exo $=$ exosome; MFI $=$ mean fluorescence intensity; UD $=$ undifferentiated.

\section{REFERENCES}

Argyropoulos, C., K. Wang, S. McClarty, D. Huang, J. Bemardo, D. Ellis, T. Orchard, D. Galas, and J. Johnson. 2013. Urinary microRNA profiling in the nephropathy of type 1 diabetes. PLoS ONE 8:e54662.

Arroyo, J. D., J. R. Chevillet, E. M. Kroh, I. K. Ruf, C. C. Pritchard, D. F. Gibson, P. S. Mitchell, C. F. Bennett, E. L. Pogosova-Agadjanyan, D. L. Stirewalt, J. F. Tait, and M. Tewari. 2011. Argonaute2 complexes carry a population of circulating microRNAs independent of vesicles in human plasma. Proc. Natl. Acad. Sci. USA 108:5003-5008.

Baier, S. R., C. Nguyen, F. Xie, J. R. Wood, and J. Zempleni. 2014. MicroRNAs are absorbed in biologically meaningful amounts from nutritionally relevant doses of cow milk and affect gene expression in peripheral blood mononuclear cells, HEK-293 kidney cell cultures, and mouse livers. J. Nutr. 144:1495-1500.

Brenaut, P., R. Bangera, C. Bevilacqua, E. Rebours, C. Cebo, and P. Martin. 2012. Validation of RNA isolated from milk fat globules to profile mammary epithelial cell expression during lactation and transcriptional response to a bacterial infection. J. Dairy Sci. 95:6130-6144

Chen, X., C. Gao, H. Li, L. Huang, Q. Sun, Y. Dong, C. Tian, S. Gao, H. Dong, D. Guan, X. Hu, Z. Shujian, L. Li, L. Zhu, Q. Yan, J. Zhang, K. Zen, and C. Y. Zhang. 2010. Identification and characterization of microRNAs in raw milk during different periods of lactation, commercial fluid, and powdered milk products. Cell Res. 20:1128-1137.

Cross, M. L., and H. S. Gill. 2000. Immunomodulatory properties of milk. Br. J. Nutr. 84:S81-S89.

Dickinson, B., Y. Zhang, J. S. Petrick, G. Heck, S. Ivashuta, and W. S. Marshall. 2013. Lack of detectable oral bioavailability of plant microRNAs after feeding in mice. Nat. Biotechnol. 31:965-967.

Gu, Y., M. Li, T. Wang, Y. Liang, Z. Zhong, X. Wang, Q. Zhou, L. Chen, Q. Lang, Z. He, X. Chen, J. Gong, X. Gao, X. Li, and X. Lv. 2012. Lactation-related microRNA expression profiles of porcine breast milk exosomes. PLoS ONE 7:e43691.

Hata, T., K. Murakami, H. Nakatani, Y. Yamamoto, T. Matsuda, and N. Aoki. 2010. Isolation of bovine milk-derived microvesicles carrying mRNAs and microRNAs. Biochem. Biophys. Res. Commun. 396:528-533. 
Haug, A., A. T. Høstmark, and O. M. Harstad. 2007. Bovine milk in human nutrition-A review. Lipids Health Dis. 6:25.

Hino, K., K. Tsuchiya, T. Fukao, K. Kiga, R. Okamoto, T. Kanai, and M. Watanabe. 2008. Inducible expression of microRNA-194 is regulated by HNF-1alpha during intestinal cell differentiation. RNA 14:1433-1442.

Izumi, H., N. Kosaka, T. Shimizu, K. Sekine, T. Ochiya, and M. Takase. 2012. Bovine milk contains microRNA and messenger RNA that are stable under degradative conditions. J. Dairy Sci. 95:4831-4841.

Izumi, H., N. Kosaka, T. Shimizu, K. Sekine, T. Ochiya, and M. Takase. 2013. Purification of RNA from milk whey. Methods Mol. Biol. 1024:191-201.

Izumi, H., N. Kosaka, T. Shimizu, K. Sekine, T. Ochiya, and M. Takase. 2014. Time-dependent expression profiles of microRNAs and mRNAs in rat milk whey. PLoS ONE 9:e88843.

Ju, S., J. Mu, T. Dokland, X. Zhuang, Q. Wang, H. Jiang, X. Xiang, Z. B. Deng, B. Wang, L. Zhang, M. Roth, R. Welti, J. Mobley, Y. Jun, D. Miller, and H. G. Zhang. 2013. Grape exosome-like nanoparticles induce intestinal stem cells and protect mice from DSS-induced colitis. Mol. Ther. 21:1345-1357.

Kosaka, N., H. Iguchi, and T. Ochiya. 2010a. Circulating microRNA in body fluid: A new potential biomarker for cancer diagnosis and prognosis. Cancer Sci. 101:2087-2092.

Kosaka, N., H. Izumi, K. Sekine, and T. Ochiya. 2010b. MicroRNA as a new immune-regulatory agent in breast milk. Silence 1:7.

Lässer, C., V. S. Alikhani, K. Ekström, M. Eldh, P. T. Paredes, A. Bossios, M. Sjöstrand, S. Gabrielsson, J. Lötvall, and H. Valadi. 2011. Human saliva, plasma and breast milk exosomes contain RNA: Uptake by macrophages. J. Transl. Med. 9:9.

Lemay, D. G., O. A. Ballard, M. A. Hughes, A. L. Morrow, N. D Horseman, and L. A. Nommsen-Rivers. 2013. RNA sequencing of the human milk fat layer transcriptome reveals distinct gene expression profiles at three stages of lactation. PLoS ONE 8:e67531.

Liu, X., Z. Zhan, L. Xu, F. Ma, D. Li, Z. Guo, N. Li, and X. Cao. 2010. MicroRNA-148/152 impair innate response and antigen presentation of TLR-triggered dendritic cells by targeting CaMKII $\alpha$. J. Immunol. 185:7244-7251.

Lukasik, A., and P. Zielenkiewicz. 2014. In silico identification of plant miRNAs in mammalian breast milk exosomes-A small step forward? PLoS ONE 9:e99963.

Maningat, P. D., P. Sen, M. Rijnkels, A. L. Sunehag, D. L. Hadsell, M. Bray, and M. W. Haymond. 2009. Gene expression in the human mammary epithelium during lactation: The milk fat globule transcriptome. Physiol. Genomics 37:12-22.

Marshall, K. 2004. Therapeutic applications of whey protein. Altern. Med. Rev. 9:136-156.

Mestdagh, P., N. Hartmann, L. Baeriswyl, D. Andreasen, N. Bernard, C. Chen, D. Cheo, P. D'Andrade, M. DeMayo, L. Dennis, S. Derveaux, Y. Feng, S. Fulmer-Smentek, B. Gerstmayer, J. Gouffon, C. Grimley, E. Lader, K. Y. Lee, S. Luo, P. Mouritzen, A. Narayanan, S. Patel, S. Peiffer, S. Rüberg, G. Schroth, D. Schuster, J. M. Shaffer, E. J. Shelton, S. Silveria, U. Ulmanella, V. Veeramachaneni, F. Staedtler, T. Peters, T. Guettouche, L. Wong, and J. Vandesompele. 2014. Evaluation of quantitative miRNA expression platforms in the microRNA quality control (miRQC) study. Nat. Methods 11:809-815.

Mitchell, P. S., R. K. Parkin, E. M. Kroh, B. R. Fritz, S. K. Wyman, E. L. Pogosova-Agadjanyan, A. Peterson, J. Noteboom, K. C. O'Briant, A. Allen, D. W. Lin, N. Urban, C. W. Drescher, B. S. Knudsen, D. L. Stirewalt, R. Gentleman, R. L. Vessella, P. S. Nel- son, D. B. Martin, and M. Tewari. 2008. Circulating microRNAs as stable blood-based markers for cancer detection. Proc. Natl. Acad. Sci. USA 105:10513-10518.

Munch, E. M., R. A. Harris, M. Mohammad, A. L. Benham, S. M. Pejerrey, L. Showalter, M. Hu, C. D. Shope, P. D. Maningat, P. H. Gunaratne, M. Haymond, and K. Aagaard. 2013. Transcriptome profiling of microRNA by next-gen deep sequencing reveals known and novel miRNA species in the lipid fraction of human breast milk. PLoS ONE 8:e50564.

Ogawa, Y., Y. Taketomi, M. Murakami, M. Tsujimoto, and R. Yanoshita. 2013. Small RNA transcriptomes of two types of exosomes in human whole saliva determined by next generation sequencing. Biol. Pharm. Bull. 36:66-75.

Papetti, M., and L. H. Auqenlicht. 2011. Mybl2, downregulated during colon epithelial cell maturation, is suppressed by miR-365. Am. J. Physiol. Gastrointest. Liver Physiol. 301:G508-G518.

Romao, J. M., W. Jin, M. He, T. McAllister, and L. Guan le. 2014. MicroRNAs in bovine adipogenesis: Genomic context, expression and function. BMC Genomics 15:137.

Sato, F., S. Tsuchiya, S. J. Meltzer, and K. Shimizu. 2011. MicroRNAs and epigenetics. FEBS J. 278:1598-1609.

Simpson, R. J., J. W. Lim, R. L. Moritz, and S. Mathivanan. 2009. Exosomes: Proteomic insights and diagnostic potential. Expert Rev. Proteomics 6:267-283.

Snow, J. W., A. E. Hale, S. K. Isaacs, A. L. Baggish, and S. Y. Chan. 2013. Ineffective delivery of diet-derived microRNAs to recipient animal organisms. RNA Biol. 10:1107-1116.

Sun, Q., X. Chen, J. Yu, K. Zen, C. Y. Zhang, and L. Li. 2013. Immune modulatory function of abundant immune-related microRNAs in microvesicles from bovine colostrum. Protein Cell 4:197-210.

van Hooijdonk, A. C., K. D. Kussendrager, and J. M. Steijns. 2000. In vivo antimicrobial and antiviral activity of components in bovine milk and colostrum involved in non-specific defence. Br. J. Nutr. 84:S127-S134.

Vickers, K. C., B. T. Palmisano, B. M. Shoucri, R. D. Shamburek, and A. T. Remaley. 2011. MicroRNAs are transported in plasma and delivered to recipient cells by high-density lipoproteins. Nat. Cell Biol. 13:423-433

Wang, H., R. A. Ach, and B. Curry. 2007. Direct and sensitive miRNA profiling from low-input total RNA. RNA 13:151-159.

Weber, J. A., D. H. Baxter, S. Zhang, D. Y. Huang, K. H. Huang, M. J. Lee, D. J. Galas, and K. Wang. 2010. The microRNA spectrum in 12 body fluids. Clin. Chem. 56:1733-1741.

Wickramasinghe, S., G. Rincon, A. Islas-Trejo, and J. F. Medrano. 2012. Transcriptional profiling of bovine milk using RNA sequencing. BMC Genomics 13:45.

Zhang, L., D. Hou, X. Chen, D. Li, L. Zhu, Y. Zhang, J. Li, Z. Bian, X. Liang, X. Cai, Y. Yin, C. Wang, T. Zhang, D. Zhu, D. Zhang, J. Xu, Q. Chen, Y. Ba, J. Liu, Q. Wang, J. Chen, J. Wang, M. Wang, Q. Zhang, J. Zhang, K. Zen, and C. Y. Zhang. 2012. Exogenous plant MIR168a specifically targets mammalian LDLAP1: Evidence of cross-kingdom regulation by microRNA. Cell Res. 22:107-126.

Zhang, Y., X. Wang, M. Zhong, M. Zhang, Q. Suo, and K. Lv. 2013. MicroRNA let-7a ameliorates con A-induced hepatitis by inhibiting IL-6-dependent Th17 cell differentiation. J. Clin. Immunol. 33:630-639.

Zhou, Q., M. Li, X. Wang, Q. Li, T. Wang, Q. Zhu, X. Zhou, X. Wang, X. Gao, and X. Li. 2012. Immune-related microRNAs are abundant in breast milk exosomes. Int. J. Biol. Sci. 8:118-123. 